American Journal of Biochemistry and Biotechnology 6 (1): 25-31, 2010

ISSN 1553-3468

(C) 2010 Science Publications

\title{
Antilithiatic Influence of Spirulina on Ethylene Glycol-Induced Nephrolithiasis in Male Rats
}

\author{
Atef M. Al-Attar \\ Department of Biological Sciences, Faculty of Sciences, King Abdul Aziz University, \\ P.O. Box 139109, Jeddah 21323, Saudi Arabia
}

\begin{abstract}
Problem statement: Nephrolithiasis or renal stone disease remains a significant health problem in the adult population. Nephrolithiasis is a recurrent disorder prominent in males. It is significant medical and surgical problem because of incidence, recurrence and severe consequences. The present day medical management of nephrolithiasis is either costly or not without side effects. Invasive procedures for the treatment of nephrolithiasis may cause serious complications and they also impose a great load of costs to the healthcare system. Hence the search for antilithiatic drugs from natural sources has assumed greater importance. Approach: The aim of the present study was to evaluate the antilithiatic activity of spirulina supplementation on ethylene glycol induced nephrolithiasis in male rats. Healthy male Wistar rats were used in the present study and were divided randomly into 4 groups. Rats of 1 st group were served as normal control. Rats of 2nd group were received $0.75 \%$ ethylene glycol in drinking water for three weeks and drinking tap water for the next three weeks. Rats of 3rd group were received $0.75 \%$ ethylene glycol in drinking water for three weeks and fed with spirulina solution $\left(20 \mathrm{mg} \mathrm{kg}^{-1}\right.$ body weight) for the next three weeks. Animals of 4 th group were treated as 1 st group for the first three weeks and fed with spirulina solution ate the same dose given to 3rd group for the last three weeks. After six weeks, serum levels of sodium, chloride, potassium, calcium, phosphorus, Blood Urea Nitrogen (BUN), uric acid, creatinine, Alanine aminotransferase (ALT), Aspartate aminotransferase (AST) were measured. Results: Statistically increases in the levels of sodium, chloride, BUN and ALT and a decrease in the level of calcium were noted in rats treated with ethylene glycol. Supplementation of spirulina for the last three weeks mostly recovered the rats from nephrolithiasis and completely from hepatotoxicity induced by ethylene glycol. Conclusion: This study suggested that spirulina is a safety and promising agent as a functional food for the management of nephrolithiasis induced by ethylene glycol and may be also by other chemical factors.
\end{abstract}

Key words: Nephrolithiasis, ethylene glycol, spirulina, serum chemistry, rats

\section{INTRODUCTION}

Nephrolithiasis (renal stone formation) is worldwide in distribution and a common disorder estimated to occur in approximately $12 \%$ of the population, with a recurrence rate of $70-80 \%$ on males and $47-60 \%$ females (Smith and Guay, 1992). The majority of stones, up to $80 \%$, are composed mainly of calcium oxalate (Daudon et al., 1993). Many remedies have been employed during ages to treat renal stones. Most of remedies were taken from plants and proved to be useful, though the rational behind their use is not will established except for a few plants and some proprietary composite herbal drugs and they are reported to be effective with no side effects (Nadkarni, 1976). The present day medical management of nephrolithiasis is either costly or not without side effects. Hence the search for antilithiatic drugs from natural sources has assumed greater importance (Verma et al., 2009).

Ethylene glycol (CASRN 107-21-1) is an intermediate in the synthesis of a number of commercial chemical products, including Polyethylene Terephthalate (PET) resins, unsaturated polyester resins and polyester fibers and films. It is also a constituent in antifreeze, deicing fluids, surface coatings, heat transfer fluids and industrial coolants, hydraulic fluids, surfactants and emulsifiers (Lockely et al., 2002). General population, or consumer, exposure occurs primarily from the use of ethylene glycol in automotive antifreeze. There have been a number of acute human poisonings from accidental or intentional ingestion of antifreeze, with the kidney being the most sensitive target organ. Regimens for the treatment of acute 
Am. J. Biochem. \& Biotech., 6 (1): 25-31, 2010

ethylene glycol poisoning are designed to prevent metabolism to the toxic acidic metabolites, to treat acidosis and to prevent kidney damage (Barceloux et al., 1999; Brent et al., 1999). Ethylene glycol has in itself a low toxicity, but is in vivo broken down to four organic acids: Glycoaldehyde, glycolic acid, glyoxylic acid and oxalic acid. The metabolites are cell toxins that cause central nervous system depression and cardiopulmonary and renal failure. Glycolic acid causes severe acidosis and oxalate is precipitated as calcium oxalate in the kidneys and other tissues (Leth and Gregersen, 2005).

Spirulina is a microscopic, an unbranched, a helicoidal, filamentous and multicellular blue-green algae or cyanobacterium belonging to algae of the class Cyanophyta. It has a long history of use as food and it is the nature's richest and most complete source of organic nutrition. The concentrated nutritional profile of spirulina occurs naturally, so it is ideal for those preferring a whole food supplement to artificial nutrient sources. Spirulina has a unique blend of nutrients that no single source can provide. It has been labeled as a powerful food, rich in proteins, carbohydrates, polyunsaturated fatty acids, sterols and some more vital elements like calcium, iron, zinc, magnesium, manganese and selenium. It is a natural source of vitamin $\mathrm{B} 12$, vitamin $\mathrm{E}$, ascorbic acid, tocopherols and whole spectrum of natural mixed carotene and xanthophylls phytopigments (Chamorro et al., 1996; Piñero Estrada et al., 2001; Chamorro et al., 2002). Spirulina is fast emerging as a whole answer to the varied demands due to its impressive nutrient composition which can be used for therapeutic uses (Venkataraman, 1998). The United Nations World Food Conference declared spirulina as "the best for tomorrow" and it is gaining popularity in recent years as a food supplement (Kapoor and Mehta, 1993). The spirulina ability as a potent anti-viral (Gustafson et al., 1989; Hayashi et al., 1993; Patterson et al., 1993; Hayashi et al., 1996; Shih et al., 2003), anti-cancer (Suda et al., 1986; Pang et al., 1988; Schwartz et al., 1988; Lisheng et al., 1991; Mathew et al., 1995; Ismail et al., 2009), hypocholesterolemic and hypolipidemic (Devi and Venkataraman, 1983; Becker et al., 1986; Nakaya et al., 1988; Iwate et al., 1990; Nagaoka et al., 2005; Colla et al., 2008), antidiabetic (Parikh et al., 2001; Muthuraman et al., 2009) and health improvement (Annapurna et al., 1991) agent is gaining attention as a nutraceutical and a source of potential pharmaceutical. Despite considerable progress in medical therapy, there is no satisfactory drug to treat kidney stones. So, the present study was designed to investigate the antilithiatic activity of spirulina supplementation on ethylene glycol induced nephrolithiasis in male rats.

\section{MATERIALS AND METHODS}

Animals: Forty male Wistar rats (185-210 g) were utilized in the current study and were obtained from the Experimental Animal Unit of King Fahd Medical Research Center, King Abdul Aziz University, Jeddah, Saudi Arabia. Animals were allocated 5 per cage. Mean daily animal room temperature ranged from 18$20^{\circ} \mathrm{C}$ and mean daily relative humidity ranged from $60-65 \%$ during the study. Light timers were set to provide a $12 \mathrm{~h}$ light $/ 12 \mathrm{~h}$ dark photoperiod. Animals were fed ad libitum on normal commercial chow and had free access to water.

Experimental protocol: Rats were divided randomly into 4 groups $(n=10)$ and were treated as follows. Animals of group 1 were untreated and served as normal control. Rats of group 2 were received $0.75 \%$ ethylene glycol in drinking water ad libitum for three weeks and drinking tap water for the next three weeks. Rats of group 3 were received $0.75 \%$ ethylene glycol in drinking water ad libitum for three weeks and fed orally with spirulina solution (20 mg kg-1 body weight/daily) for the next three weeks. Rats of group 4 were treated as group 1 for the first three weeks and fed with spirulina solution ate the same dose given to group 3 for the last three weeks.

Serum chemistry analysis: After six weeks, animals were anaesthetized with diethyl ether. Blood was collected from orbital venous plexus in non-heparinized tubes and centrifuged at $2000 \mathrm{rpm}$ for $20 \mathrm{~min}$ to obtain serum. Serum levels of sodium, chloride, potassium, calcium, phosphorus, Blood Urea Nitrogen (BUN), uric acid, creatinine, Alanine aminotransferase (ALT), Aspartate aminotransferase (AST) were evaluated using Automated Clinical Chemistry Analysis System, Dimension ${ }^{\circledR}$ type RXL Max (Dade Behring Delaware, DE 19714, USA).

Statistical analysis: Data are presented as mean \pm Standard Deviation (SD) and were analyzed by oneway Analysis Of Variance (ANOVA) followed by Tukey's test for multiple comparison among all groups. Differences below $\mathrm{p}<0.05$ implied significance. Statistical Package for Social Sciences (SPSS for windows, version 12.0) was used for this analysis. 


\section{RESULTS}

The concentrations of serum electrolytes are shown in Fig. 1. The level of sodium was significantly elevated in rats treated with ethylene glycol (Group 2) compared with control value, while there were no significant changes in the values of serum sodium in rats treated with ethylene glycol plus spirulina (Group 3) or only spirulina (Group 4). In comparison with control group, there was a significant elevation in the values of serum chloride in rats supplemented with only spirulina. Statistically increase in the level of chloride was noted in rats treated with ethylene glycol compared with ethylene glycol plus spirulina treated
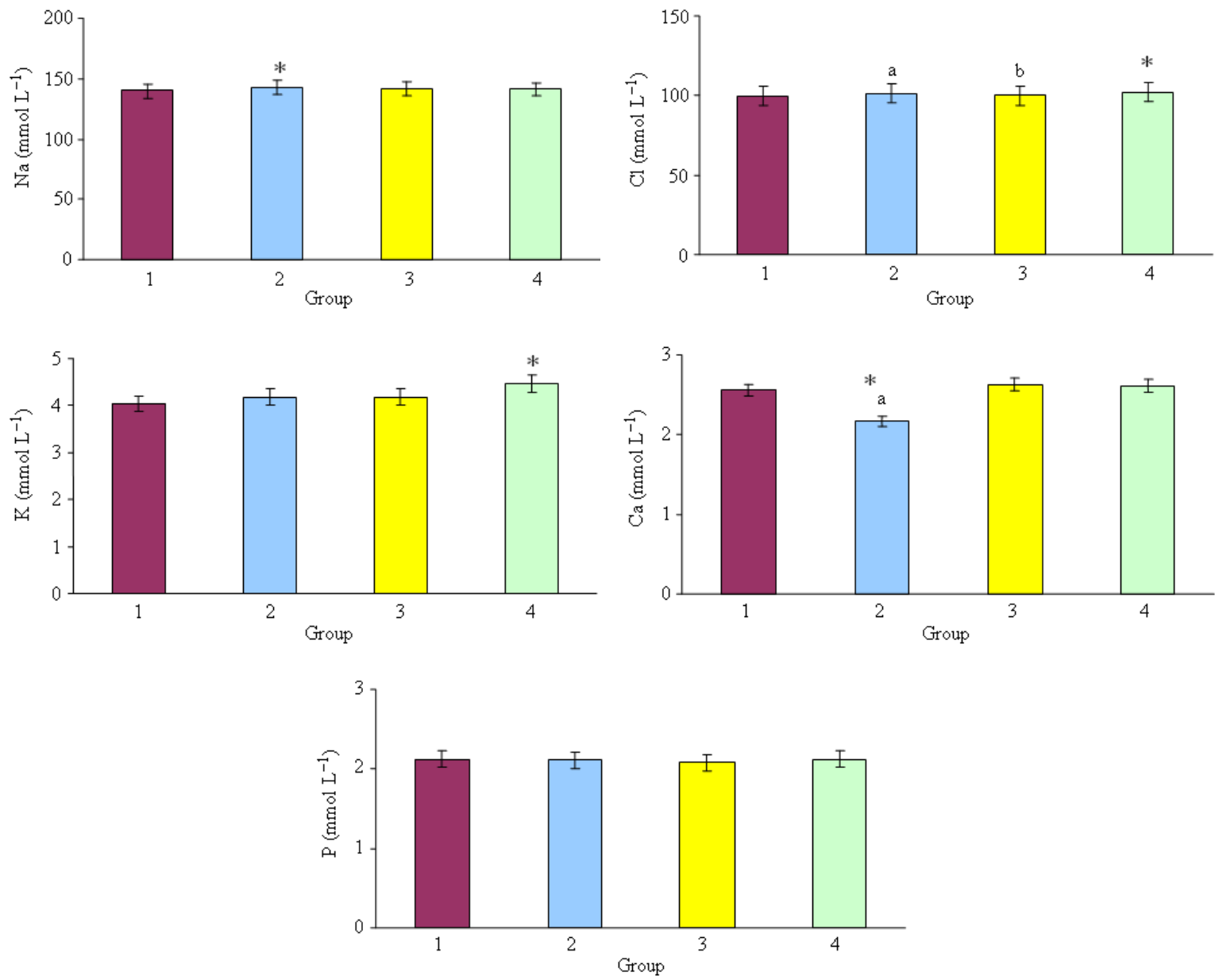

Fig. 1: Serum electrolytes (Na, Cl, K, Ca and P) values of control (Group 1), ethylene glycol (Group 2), ethylene glycol plus spirulina (Group 3) and spirulina (Group 4) treated rats $(\mathrm{n}=6)$. (*) Indicates a significant difference between control and treated groups. (a) Indicates a significant difference between ethylene glycol treated group and group treated with ethylene glycol plus spirulina; (b) Indicates significant difference between ethylene glycol plus spirulina treated group and group treated with only spirulina 
Am. J. Biochem. \& Biotech., 6 (1): 25-31, 2010
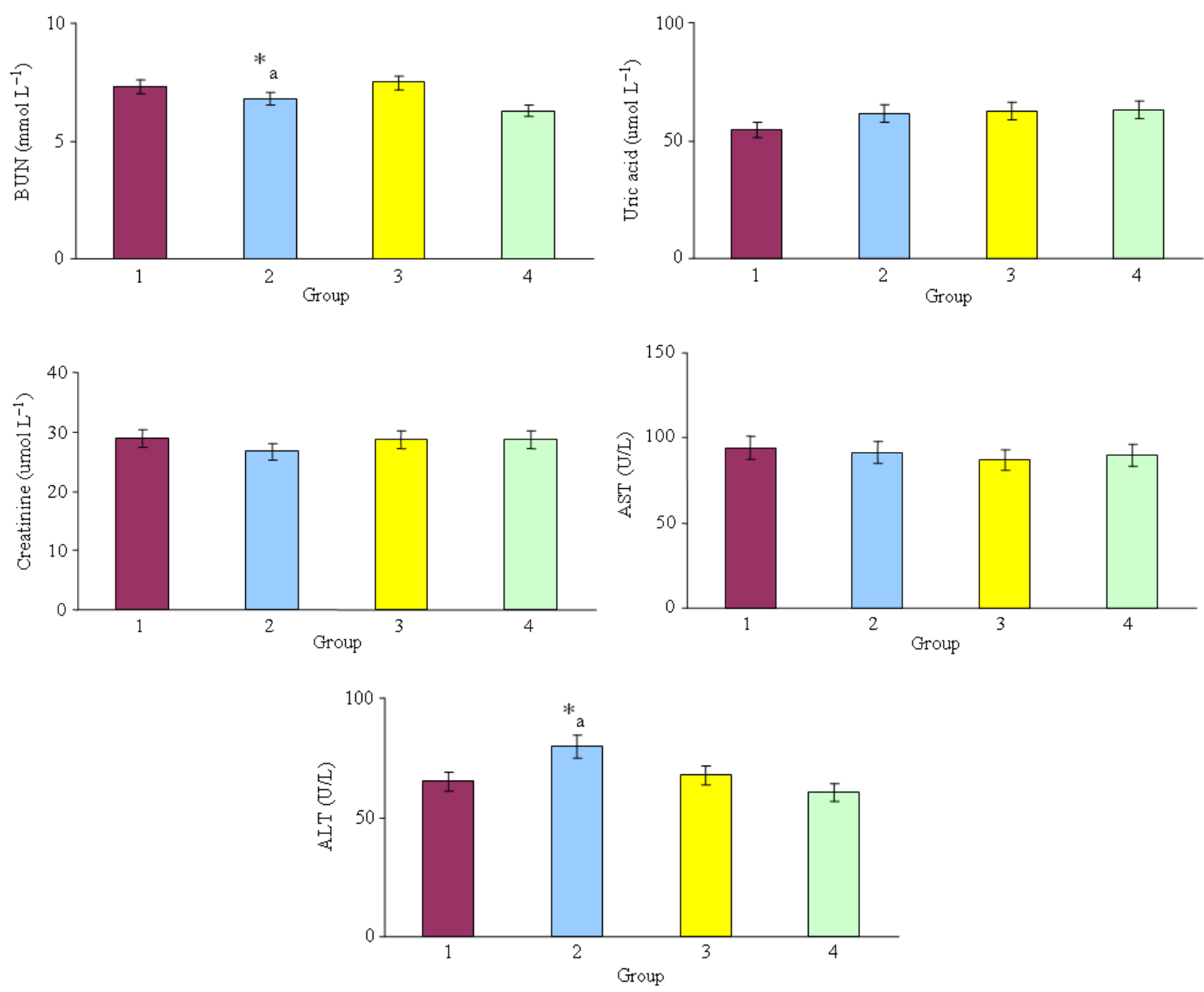

Fig. 2: Serum BUN, uric acid, creatinine, ALT and AST values of control (Group 1), ethylene glycol (Group 2), ethylene glycol plus spirulina (Group 3) and spirulina (Group 4) treated rats $(n=6)$. (*) Indicates a significant difference between control and treated groups. (a) Indicates a significant difference between ethylene glycol treated group and group treated with ethylene glycol plus spirulina

Table 1: Percentage changes in the values of serum chemical parameters in the experimental rats treated with ethylene glycol, ethylene glycol plus spirulina and spirulina compared with control values

\begin{tabular}{lcll}
\multicolumn{4}{c}{ with control values } \\
& Treatments & & \\
& - & & \\
& & Ethylene & \\
Plycol + spirulina & Spirulina \\
\hline $\mathrm{Na}$ & Ethylene glycol & +1.31 & +1.19 \\
$\mathrm{Cl}$ & +2.03 & +0.50 & +2.34 \\
$\mathrm{~K}$ & +1.51 & +3.71 & +10.92 \\
$\mathrm{Ca}$ & +3.72 & +2.73 & +1.95 \\
$\mathrm{P}$ & -15.63 & -1.89 & -0.94 \\
$\mathrm{BUN}$ & -0.47 & -2.05 & -2.74 \\
Uric acid & +16.85 & +15.35 & +16.27 \\
Creatinine & +13.51 & -0.56 & -0.59 \\
ALT & -7.53 & +4.35 & -7.19 \\
AST & +22.82 & -7.26 & -4.78 \\
\hline
\end{tabular}

The levels of BUN and ALT were markedly increased in rats treated with ethylene glycol (Group 2) compared with control group and rats groups treated with ethylene glycol plus spirulina (Group 3) and only spirulina (Group 4). The values of serum uric acid, creatinine and AST were remarkably unchanged in all treated groups compared with control values (Table 1). Also, insignificant changes in the levels of serum calcium and ALT were observed in rats treated with ethylene glycol plus spirulina and only spirulina compared with control level.

\section{DISCUSSION}

The present results showed that the administration of ethylene glycol caused statistically increases in the 
levels of sodium, chloride, BUN and ALT and a decrease in the level of calcium. Sodium and chloride ions excretion from the body is a function of arterial blood pressure (Guyton and Hall, 2006). Sodium depletion stimulates rennin release and subsequence production of Angiotensin II, a potent vasoconstrictor (Guyton and Hall, 2006). Increased blood sodium levels inhibit rennin release from the juxtaglomerular cells and consequent withdrawal of angiotensin II (Jackson and Kotchen, 1984). When modulation of the renninangiotensin system is pharmacologically prevented, changes in salt intake markedly affect long term levels of arterial blood pressure (Hall et al., 1999). There is therefore a need to strike a balance in the levels of blood sodium and chloride to avoid either of the extreme of hypotension or hypertension. Kang et al. (2002) reported that the hypernatremia is rare but does occur when there is loss of body fluids containing less sodium than blood along with water intake restriction or if there is excessive sodium intake with limited liquid intake. Vogt et al. (2009) reported that the hypernatremia almost always indicates water depletion. The present increase of serum sodium level is suspected to be due to the inability of the kidneys to excrete adequate sodium from the tubular fluid. Also, the levels of BUN and ALT were significantly increased as a strong indication of renal and hepatic impairment. The decrease of serum calcium concentration indicates an increase of urinary calcium and calcium oxalate stone formation. This suggestion is in agreement with several studies like Rajagopal et al. (1977) who reported that the level of serum calcium was decreased and urinary calcium increased in rats treated with ethylene glycol. Moreover, Soundararajan et al. (2006) showed that calcium oxalate excretion was significantly increased in urine of ethylene glycol induced urolithic rats. Additionally, they stated that ethylene glycol disturbs oxalate metabolism by way of increase the substrate availability that increase the activity of oxalate synthesizing enzymes in rats. Moreover, several investigations demonstrated that ethylene glycol treatment increased urinary calcium excretion significantly in lithiatic rats (Christina et al., 2002; Karadi et al., 2006; Verma et al., 2009). Insignificant changes in the levels of serum sodium, calcium, potassium, phosphorus, uric acid, creatinine and the activities of ALT and AST were observed in rats treated with ethylene glycol plus spirulina. These findings indicate that rats supplemented with spirulina for the last three weeks were mostly recovered from nephrolithiasis and completely from hepatotoxicity induced by ethylene glycol at the first three weeks. Nephrolithiasis and hepatotoxicity induction by ethylene glycol was established in many researches (Christina et al., 2002; Atmani et al., 2003; Huang et al., 2006; Karadi et al., 2006; Celik and Suzek, 2007; Hadjzadeh et al., 2007; Hadjzadeh et al., 2008; Verma et al., 2009; Divaka et al., 2010). The mechanism underlying the effect of spirulina on nephrolithiasis induced by ethylene glycol is still unknown, but is apparently related to increased diuresis and lowering of urinary concentrations of stone forming constituents. Further investigation is needed to explore the exact active principles responsible for the antilithiatic activity of spirulina and its mechanism of action.

\section{CONCLUSION}

Kidney stone disease has afflicted humankind since antiquity and can persist, with serious medical consequences, throughout a patient's lifetime. In addition, the incidence of kidney stones has been increased in most societies in the last five decades, especially in association with economic development. In spite of tremendous advances in the field of medicine, there is no truly satisfactory drug for the treatment of nephrolithiasis. Recently, there is increasing evidence that many healthy natural food and medicinal herbal and supplements have the potential to become valuable complementary therapy in the treatment of various renal disorders and in the protection against iatrogenic nephrotoxicity. The present study indicates that the administration of spirulina solution to rats with ethylene glycol induced nephrolithiasis reduced and prevented the growth of kidney stones, renal and hepatic impairment. Accordingly, it can be concluded that the supplementation of spirulina has a beneficial effect on nephrolithiasis induced by ethylene glycol and may be also by other chemical factors.

\section{REFERENCES}

Annapurna, V., N. Shah, P. Bhaskaran, S.M. Bamji and V. Reddy, 1991. Bioavailability of spirulina carotenes in preschool children. J. Clin. Biochem. Nutr., 10: 145-151. http://www.antenna.ch/en/documents/AspectNut_UK.pdf

Atmani, F., Y. Slimani, M. Mimouni and B. Hacht, 2003. Prophylaxis of calcium oxalate stones by herniaria hirsuta on experimentally induced nephrolithiasis in rats. BJU. Int., 92: 137-140. PMID: 12823398

Barceloux, D.G., E.P. Krenzelok, K. Olson and W. Watson, 1999. American academy of clinical toxicology practical guidelines on the treatment of ethylene glycol poisoning. J. Toxicol. Clin. Toxicol., 37: 537-560. PMID: 10497633 
Becker, E.W B. Jakover, D. Luft and R.M. Schmuelling, 1986. Clinical and biochemical evaluations of spirulina with regard to its application in the treatment of obesity. Nutr. Rep. Int., 33: 565-574. http://www.scielo.br/pdf/babt/v51n2/a22v51n2.pdf

Brent, J., K. Mc Martin, S. Phillips, K.K. Burkhart and J.W. Donovan et al., 1999. Fomepizole for the treatment of ethylene glycol poisoning. N. Engl. J. Med., 340: 832-838. PMID: 10080845

Celik, I. and H. Suzek, 2007. Effects of subacute treatment of ethylene glycol on serum marker enzymes and erythrocyte and tissue antioxidant defense systems and lipid peroxidation in rats. Chem. Biol. Interact., 167: 145-152. PMID: 17382310

Chamorro, G., M. Salazar, K.G. Araújo, C.P. dos Santos and G. Ceballos et al., 2002. Update on the pharmacology of Spirulina (Arthrospira), an unconventional food. Arch. Latinoam. Nutr., 52: 232-240. PMID: 12448336

Chamorro, G., M. Salazar, L. Favila and H. Bourges, 1996. Pharmacology and toxicology of Spirulina alga. Rev. Invest. Clin., 48: 389-399. PMID: 9005517

Christina, A.J., L.M. Packia, M. Nagarajan and S. Kurian, 2002. Modulatory effect of cyclea peltata Lam. on stone formation induced by ethylene glycol treatment in rats. Methods Find. Exp. Clin. Pharmacol., 24: 77-79. PMID: 12040886

Colla, L.M., A.M. Muccillo-Baisch and J.A.V. Costa, 2008. Spirulina platensis effects on the levels of total cholesterol, HDL and triacylglycerols in rabbits fed with a hypercholesterolemic diet. Braz. Arch. Biol. Technol., 51: 405-411. http://www.scielo.br/pdf/babt/v51n2/a22v51n2.pdf

Daudon, M., C.A. Bader and P. Jungers, 1993. Urinary calculi: Review of classification methods and correlations with etiology. Scan. Micros., 7: 1081-1104. PMID: 8146609

Devi, M.A. and L.V. Venkataraman, 1983. Hypocholesterolemic effect of blue-green algae spirulina on albino rats. Nutr. Rep. Int., 28: 519-530. http://www.idb.hr/diabetologia/06no2-1.pdf

Divaka, K., A.T. Pawar, S.B. Chandrasekhar, S.B. Dighe and G. Divakar, 2010. Protective effect of the hydro-alcoholic extract of Rubia cordifolia roots against ethylene glycol induced urolithiasis in rats. Food Chem. Toxicol. in print. PMID: 20079795

Gustafson, K.R., J.H. Cardellina, R.W. Fuller, O.S. Weislow and R.F. Kiser et al., 1989. AIDS antiviral sulfolipids from cyanobacteria (blue-green algae). J. Natl. Cancer Inst., 81: 1254-1258. PMID: 2502635
Guyton, A.C. and J.E. Hall, 2006. Textbook of Medical Physiology. 11th Edn., Elsevier and Saunders, Philadelphia, ISBN: 9780721602400, pp: 358-382.

Hadjzadeh, M.A., A. Khoei, Z. Hadjzadeh and M. Parizady, 2007. Ethanolic extract of Nigella sativa L seeds on ethylene glycol-induced kidney calculi in rats. Urol. J., 4: 86-90. PMID: 17701927

Hadjzadeh, M.A., N. Mohammadian, Z. Rahmani and F.B. Rassouli, 2008. Effect of thymoquinone on ethylene glycol-induced kidney calculi in rats. Urol. J., 5: 149-155. PMID: 18825620

Hall, J.E., M.W. Brands and J.R. Henegar, 1999. Angiotensin II and long term arterial pressure regulation: The overriding dominance of the kidney. J. Am. Soc. Nephrol., 10: S258-265. PMID: 10201880

Hayashi, K., T. Hayashi, N. Morita and I. Kojima, 1993. An extract from Spirulina platensis is a selective inhibitor of herpes simplex virus type 1 penetration into cells. Phytother. Res., 7: 76-80. DOI: $10.1002 /$ ptr.2650070118

Hayashi, T., K. Hayashi, M. Maeda and I. Kojima, 1996. Calcium spirulan, an inhibitor of enveloped virus replication, from a bluegreen alga Spirulina platensis. J. Nat. Prod., 59: 83-87. PMID: 8984158

Huang, H.S., M.C. Ma, C.F. Chen and J. Chen, 2006. Changes in nitric oxide production in the rat kidney due to $\mathrm{CaOx}$ nephrolithiasis. Neurourol. Urodyn., 25: 252-258. PMID: 16496394

Ismail, M.F., D.A. Ali, A. Fernando, M.E. Abdraboh and R.L. Gaur et al., 2009. Chemoprevention of rat liver toxicity and carcinogenesis by Spirulina. Int. J. Biol. Sci., 5: 377-387. PMID: 19521547

Iwate, K., T. Inayama and T. Kato, 1990. Effects of Spirulina platensis on plasma lipoprotein lipase activity in fructose induced hyperlipidemia in rats. J. Nutr. Sci. Vitaminol., 36: 165-171. PMID: 2117648

Jackson, B.A. and T.A. Kotchen, 1984. Salt sensitive hypertension contribution of chloride. Science, 223: 1430-1432. DOI: 10.1126/science.6322303

Kang, S., W. Kim, M.S. Oh, 2002. Pathogenesis and treatment of hypernatremia. Nephron, 92: 14-17. PMID: 12401933

Kapoor, R. and U. Mehta, 1993. Effect of supplementation of blue green algae on outcome of pregnancy of rats. Plant Foods Hum. Nutr., 43: 29-35. DOI: 10.1007/BF01088093

Karadi, R.V., N.B. Gadge, K.R. Alagawadi and R.V. Savadi, 2006. Effect of Moringa oleifera Lam. root-wood on ethylene glycol induced urolithiasis in rats. J. Ethnopharmacol., 105: 306-311. PMID: 16386862 
Leth, P.M. and M. Gregersen, 2005. Ethylene glycol poisoning. Forensic Sci. Int., 155: 179-184. DOI: $10.1007 / 978-0-387-84843-3 \_11$

Lisheng, L., G. Baojiang, R. Jihong, Q. Guangquan and W. Botang, 1991. Inhibitive effect and mechanism of polysaccharide of Spirulina platensis on transplanted tumor cells in mice. Marine Sci., 5: 33-38. DOI: 1000-3096.0.1991-05-013

Lockely, D.J., D. Howes and F.M. Williams, 2002. Percutaneous penetration and metabolism of 2ethoxyethanol. Toxicol. Applied Pharmacol., 180: 74-82. PMID: 11969374

Mathew, B., R. Sankaranarayanan, P.P. Nair., C. Varghese and T. Somanathan et al., 1995. Evaluation of chemoprevention of oral cancer with Spirulina fusiformis. Nutr. Cancer, 24: 197-202. PMID: 8584455

Muthuraman, P., R. Senthilkumar and K. Srikumar, 2009. Alterations in beta-islets of Langerhans in alloxan-induced diabetic rats by marine Spirulina platensis. J. Enz. Inhib. Med. Chem., 24: 1253-1256. PMID: 19912059

Nadkarni, K.M., 1976. Indian Materica Medica. 3rd Edn., Popular Book Depto, Bombay, ISBN: 817154-143-7, pp: 371.

Nagaoka, S., K. Shimizu, H. Kaneko, F. Shibayama and K. Morikawa et al., 2005. A novel protein Cphycocyanin plays a crucial role in the hypocholesterolemic action of Spirulina platensis concentrate in rats. J. Nutr., 135: 2425-2430.

Nakaya, N., Y. Homma and Y. Goto, 1988. Cholesterol lowering effect of spirulina. Nutr. Rep. Int., 37: 1329-1337.

http://grande.nal.usda.gov/ibids/index.php?mode2= detail\&origin=ibids_references\&therow $=423615$

Pang, Q.S., B.J. Guo and J.H. Ruan, 1988. Enhancement of endonuclease activity and repair DNA synthesis by polysaccharide of Spirulina platensis. Yi Chuan Xue Bao., 15: 374-381. PMID: 2856229

Parikh, P., U. Mani and U. Iyer, 2001. Role of Spirulina in the control of glycemia and lipidemia in type 2 diabetes mellitus. J. Med. Food, 4: 193-199. PMID: 12639401

Patterson, G.M.L. , K.K. Baker, C.L. Baldwin, C.M. Bolis and F.R. Caplan et al., 1993. Antiviral activity of cultured blue-green algae (Cyanophyta). J. Phycol., 29: 125-130. DOI: 10.1111/j.1529-8817

Piñero Estrada, J.E., P. Bermejo Bescós and A.M. Villar del Fresno, 2001. Antioxidant activity of different fractions of Spirulina platensis protean extract. Farmaco, 56: 497-500. PMID: 11482785
Rajagopal, G., K. Venkatesan, P. Ranganathan and S. Ramakrishnan, 1977. Calcium and phosphorus metabolism in ethylene glycol toxicity in rats. Toxicol. Applied Pharmacol., 39: 543-547. DOI: 10.101/0041-008X(770901 45-4)

Schwartz, J., G. Shklar, S. Reid and D. Trickler, 1988. Prevention of experimental oral cancer by extracts of Spirulina-Duraliella algae. Nutr. Cancer, 11: 127-134. PMID: 3129701

Shih, S.R., K.N. Tsai, Y.S. Li, C.C. Chueh and E.C. Chan, 2003. Inhibition of enterovirus 71-induced apoptosis by allophycocyanin isolated from a bluegreen alga Spirulina platensis. J. Med. Virol., 70: 119-125. PMID: 12629652

Smith, C.L. and D.R.P. Guay, 1992. Nephrolithiasis. In: Pharmacotherapy: A Pathophysiologic Approach, DiPiro, J.T., R.L. Talbert, P.E. Hayes, G.C. Yee, G.R. Matzke and L.M. Posey (Eds.), 2nd Edn., Elsevier, New York, ISBN: 0838579760, pp: 720.

Soundararajan, P., R. Mahesh, T. Ramesh and V.H. Begum, 2006. Effect of Aerva lanata on calcium oxalate urolithiasis in rats. Indian J. Exp. Biol., 44: 981-986. PMID: 17176671

Suda, D., J. Schwartz and G. Shklar, 1986. Inhibition of experimental oral carcinogenesis by tropical beta carotene. Carcinogenesis, 7: 711-715. PMID: 3084114

Venkataraman, L.V., 1998. Spirulina: Global reach of a health care product. Souvenir. IFCON '98, 4th International Food Convention, pp: 175.

Verma, N.K., S.S. Patel, T.S.M. Saleem, A.J.M. Christina and N. Chidambaranathan, 2009. Modulatory effect of noni-herbal formulation against ethylene glycol-induced nephrolithiasis in albino rats. J. Pharm. Sci. Res., 1: 83-89. http://www.jpsr.pharmainfo.in/Documents/Volume s/.../pdf/jpsr01030911.pdf

Vogt, B., L. Berwert and M. Burnier, 2009. Hypernatremia. Ther. Umsch., 66: 753-757. PMID: 19885793 